\title{
SOBRE LA POLARIDAD SIMPATÍA-ANTIPATÍA EN LA INTERPRETACIÓN HIPOCRÁTICA DE LA PHÝSIS HUMANA
}

\author{
Ruy J. HenríQuez GarRido \\ Universidad Complutense de Madrid \\ bttp://dx.doi.org/10.15304/ag.38.2.5614
}

\section{Resumen}

El propósito de este artículo es estudiar, en el contexto de la epistemología médica hipocrática, la importancia del par antitético simpatía-antipatía, como instrumento interpretativo de la phýsis humana. Con ello se pretende aportar comprensión a los métodos de inferencia desarrollados por la medicina antigua, de forma alternativa al método demostrativo. Palabras clave: simpatía, antipatía, razonamiento por analogía, abducción, signos, polaridad, enantíosis.

\section{Abstract}

The purpose of this paper is studying the importance of the antithetical pair sympathyantipathy, as an interpretive instrument of the human physis in the Hippocratic medical epistemology. His study aims to be a contribution to the understanding of the methods of inference developed by ancient medicine, in parallel to the demonstrative method.

Keywords: sympathy, antipathy, reasoning by analogy, abduction, signs, polarity, enantiosis.

Recibido: 15/11/2018. Aceptado: 24/01/2019. 


\section{Introducción}

A lo largo de este trabajo intentaré definir el papel que juega el par antitético simpatía-antipatía, dentro de la epistemología médica hipocrática, como instrumento interpretativo de la phýsis humana y sus procesos orgánicos. Si bien, el desarrollo cumbre de este par conceptual se alcanza con el Estoicismo y el Neoplatonismo, no supone ningún anacronismo investigar sus orígenes en el pensamiento presocrático y su influencia en la medicina hipocrática ${ }^{1}$. Mi tarea, por tanto, será mostrar que los principios racionales que rigen su funcionamiento en el pensamiento médico hipocrático, hunden sus raíces en la filosofía de la naturaleza presocrática. Para ello expondré de forma sucinta cómo las nociones de simpatía (atracción) y antipatía (repulsión), en la base del razonamiento por analogía ${ }^{2}$, jugaron un destacado

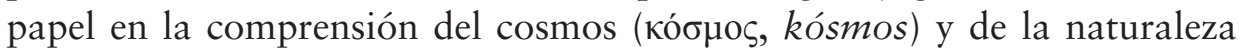
( $\varphi v ́ \sigma l \varsigma$, phýsis).

La progresiva definición de las enfermedades, el reconocimiento y la clasificación de los signos con los que se manifiestan (cĩoş), así como la comprensión del funcionamiento de cada órgano en relación al conjunto del cuerpo humano, en medio de insalvables dificultades para la observación, fueron algunos de los motivos que llevaron a la medicina hipocrática a establecer formas de inferencia particulares, antes de generalizarse el método demostrativo aristotélico.

De un modo incipiente, el uso de la relación polar simpatía-antipatía permitió establecer formas de prueba empírica e inductiva que definirían criterios de observación y niveles de certeza en la inferencia causal, con los que poder llevar a cabo diagnósticos y tratamientos.

Esta relación antitética es un caso ejemplar del extendido uso, dentro del

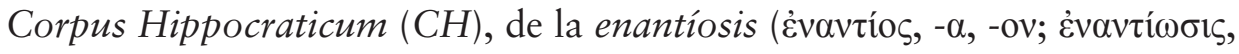
$-\varepsilon \omega \varsigma, \dot{\eta})$ o "apareamiento de los contrarios" 3.

1 Sobre las tendencias "proto-simpáticas" en el Corpus Hippocraticum ver Holmes (2014).

${ }^{2}$ Las definiciones básicas de los términos "analogía”, "afinidad” y "simpatía”, aquí relacionados, revelan los múltiples aspectos que posee el concepto de semejanza y, en última instancia, las diversas formas que puede adquirir el razonamiento por analogía, en torno al cual están unidos. Las relaciones de simpatía-antipatía, hasta épocas muy recientes, fueron "el principio supremo de la similitud"; Foucault (1981), pp. 26-34. En el presente contexto, interpretamos el razonamiento por analogía como la inferencia que, partiendo de lo que se puede ver o entender, permite extraer conclusiones prácticas acerca de lo que no puede ser percibido o comprendido fácilmente.

${ }^{3}$ Laín Entralgo (1982); Lloyd (1987); Martínez (2004). 
En primer lugar, examinaré la relación de la parte al todo y su importancia para entender la unidad de la naturaleza física en general y el cuerpo humano en particular. A continuación, consideraré el papel del principio de lo igual hacia lo igual en el estudio de procesos complejos. En el siguiente apartado, analizaré la importancia de los términos de isonomía y monarquía en la idea de salud de la medicina hipocrática. Finalmente, intentando hacer acopio de lo investigado, definiré el modo de razonamiento por oposición y semejanza que creo ocupa un lugar importante en el $\mathrm{CH}$. Para cerrar, intentaré extraer brevemente algunas conclusiones.

El estudio de los métodos pre-lógicos de inferencia utilizados en la medicina hipocrática resulta de suma importancia para comprender mejor los orígenes del pensamiento racional y formal, así como los antecedentes del conocimiento probable. La polaridad aquí expuesta constituye un ejemplo de método inductivo primitivo gracias al cual una intuición de sentido común, de índole esencialmente cualitativa, llegaría a ser, con el desarrollo del pensamiento y de la ciencia, el antecedente de algunos de los principios cuantitativos que hoy rigen la medicina ${ }^{4}$.

\section{Relación de la parte al todo}

Aunque la transformación de la racionalidad suele describirse como radical respecto al periodo arcaico, resulta innegable que el pensamiento mítico poseyó recursos que habrían de perdurar en el pensamiento lógico y filosófico posterior. Uno de estos recursos fue el uso de opuestos (enantíosis) ${ }^{5}$ en la interpretación de un gran número de fenómenos de carácter complejo $^{6}$. La enantíosis constituyó una piedra angular del pensamiento presocrático y su uso se habría de prolongar más allá del surgimiento de la lógica formal.

Una de las unidades enantióticas más importantes es la que conformaron la simpatía y la antipatía. La interpretación del término simpatía que aquí interesa destacar, se refiere principalmente a la afinidad bajo la forma de atracción, influencia o semejanza entre dos o más elementos, de un conjunto o sistema ${ }^{7}$. El uso de este término, así como la intuición de unidad que lo

${ }^{4}$ Un ejemplo del camino de lo cualitativo a lo cuantitativo en Fleck (1986b).

${ }^{5}$ Snell (2007), p. 370; Lloyd (1987), p. 66.

${ }^{6}$ Lloyd (1987), p. 81.

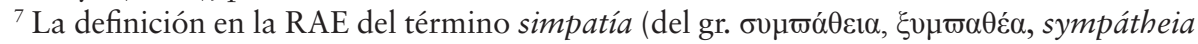

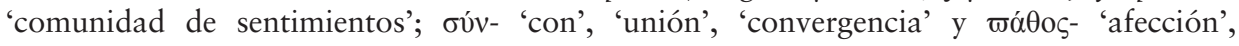
'padecimiento', 'sentimiento') contiene dos acepciones que avalan su uso en el contexto 
sostiene, constituye una característica estrechamente vinculada a la concepción de la naturaleza ( $p h y ́ s i s$ ), en tanto que conjunto ordenado (kósmos), que contrasta con la idea de multiplicidad y fragmentación de un mundo en permanente cambio, implícita en el pensamiento arcaico $^{8}$. De esta visión totalizadora ofrece constancia el $\mathrm{CH}$ en numerosas ocasiones:

Todas las cosas, así el alma del hombre, y el cuerpo igual que el alma, están implicadas en un orden. ${ }^{9}$

La antítesis simpatía-antipatía tuvo consecuencias determinantes para el pensamiento filosófico y científico posterior. A pesar de su caída en desuso en el lenguaje científico actual, a consecuencia de la depuración de las llamadas "causas ocultas" que el modelo mecanicista promovió en la ciencia, todavía hoy puede constatarse su presencia en distintos ámbitos científicos, incluida la propia medicina ${ }^{10}$.

Asumiendo la unidad y el orden de la phýsis, la medicina pudo dejar atrás el pensamiento arcaico mágico-religioso ${ }^{11}$, que consideraba el cuerpo humano como una pluralidad de elementos animados por fuerzas distintas y no un sistema orgánico integrado ${ }^{12}$. En los documentos antiguos el cuerpo vivo estaba conformado por una multiplicidad de funciones anatómicas descritas, no obstante, con exhaustiva precisión ${ }^{13}$. Solo a partir del siglo $\mathrm{V}$ a.C., con la fisiología de la Grecia clásica, pudo alcanzarse la idea del cuerpo como un organismo cuyas partes forman un todo animado.

El influjo de la filosofía de la naturaleza fue determinante para dar este paso. Desde la crítica de Parménides a la concepción arcaica y de sentido común, del mundo como transformación permanente, el desafío para los

médico: “4. f. Biol. Relación de actividad fisiopatológica entre órganos sin conexión directa. / 5. f. Fís. Relación entre dos cuerpos o sistemas por la que la acción de uno induce el mismo comportamiento en el otro."

${ }^{8}$ Jaeger (1990), p. 159.

9 “Sobre la dieta”, Hipócrates (1986), p. 28; Vict. [iv] Insomn (Littré VI, p. 479). Cito la traducción castellana del $\mathrm{CH}$, a continuación la abreviatura latina de Liddell y Scott (1940) y, entre paréntesis, volumen, número de apartado y página de la edición de Littré (1962).

${ }^{10}$ En inmunología, la afinidad es definida como la fuerza de interacción entre antígeno y anticuerpo. Otros ejemplos destacados son la "afinidad selectiva" (biología) y "afinidad química” (farmacología y toxicología). Sobre el desarrollo del concepto de afinidad ver Estany-Izquierdo (1990).

${ }^{11}$ Jaeger (1990), pp. 785-786.

${ }^{12}$ Laín Entralgo (1987), pp. 72-73; Snell (2007), p. 29. Ver Lasso de la Vega (1963) y Luis Gil (2004).

${ }^{13}$ Reale (1999), pp. 15-40; Snell (2007), pp. 18 y ss. Sobre la pluralidad de términos anatómicos usados en la antigüedad y su precisión descriptiva ver Albarracín Teulón (1970). 
filósofos de la naturaleza consistió en descubrir la unidad dentro de la diversidad, explicando el cambio y el movimiento. Anaximandro, Alcmeón de Crotona, Heráclito, Empédocles, Anaxágoras, Demócrito y los pitagóricos, fueron algunos de los principales artífices de la noción de phýsis y su interpretación por la antítesis de atracción-repulsión (simpatía-antipatía), asociadas a otras formas primordiales de enantíosis. Sin las unidades enantióticas presentes en la filosofía presocrática sería imposible comprender la práctica médica hipocrática ${ }^{14}$.

Un aspecto a destacar de la phýsis, integrada por los principios de la afinidad, es la cuestión de la relación de la parte al todo. Si Anaximandro y Heráclito habían concebido la phýsis como un espacio de lucha entre opuestos, y Empédocles había conseguido hacer una síntesis de cuatro elementos o "raíces", Anaxágoras, partiendo de la idea de una mezcla primordial, añade a estas formas de pluralismo integral las nociones de semillas

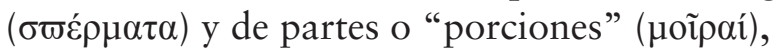

Y puesto que las porciones de lo grande y de lo pequeño son iguales en número, también todas las cosas están en todo. Tampoco es posible que existan separadas, sino que todas tienen una porción de todo. Ya que no es posible que exista la parte más pequeña, nada puede ser separado ni llegar al ser por sí mismo, sino que todas las cosas deben estar juntas como lo estuvieron originalmente. En todas hoy muchos ingredientes, iguales en número, tanto en las más grandes como en las más pequeñas de las que están siendo separadas. (DK 59 [46] в 6, p. 35) ${ }^{15}$

La conocida sentencia "En todo hay partes de todo" (DK 59 [46] в 11, p. 37), que resume la idea de pluralidad-unidad de Anaxágoras, significa que en cada cosa "están todas las cosas juntas", como en la mezcla original (DK 59 [46] в 12, p. 37) ${ }^{16}$. Las porciones no solo poseen una parcialidad de la totalidad, sino que contienen todos los componentes que constituyen el todo. Aristóteles se refirió a la teoría de las semillas de Anaxágoras

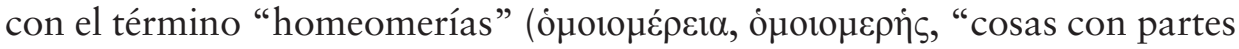
iguales"). Tales homeomerías, junto con los opuestos, serían los elementos primarios, que componen la totalidad, por ser similares al conjunto y por prevalecer sobre los demás componentes ${ }^{17}$.

Empédocles había explicado el cambio y el movimiento utilizando los polos antitéticos de unidad y pluralidad, legislados a su vez por los princi-

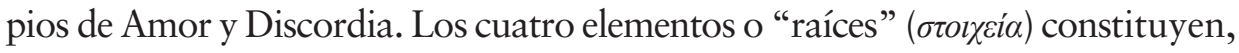

\footnotetext{
${ }^{14}$ Laín Entralgo (1982), p. 80.

${ }^{15}$ Kirk-Raven (1987), p. 511.

${ }^{16}$ Kirk-Raven (1987), p. 512.

${ }^{17}$ Kirk-Raven (1987), p. 526.
} 
junto con estos dos principios de ordenación cósmica, el núcleo fundamental de su phýsis.

... en un tiempo ellas (las raíces) llegaron a ser solo uno a partir de una pluralidad y, en otro, pasaron de nuevo a ser plurales a partir de ser uno; dúplice es la génesis de los seres mortales y doble su destrucción. A la una la engendra y la destruye su reunión y la otra crece y se disipa a medida que nacen nuevos seres por separación. Jamás cesan en su constante intercambio, confluyendo unas veces en la unidad por efecto del Amor y separándose otras por la acción del odio de la Discordia. Así, en la medida en que lo uno ha aprendido a desarrollarse a partir de lo múltiple y la pluralidad surge de nuevo de la división de lo uno, de la misma manera nacen y no tienen una vida estable. Y en la medida en que jamás cesa su continuo intercambio, así también existen inmóviles siempre en su ciclo. (DK 31 [21] в 17, 5-10, pp. 315-316) ${ }^{18}$

Empédocles, al igual que Heráclito, entiende que pese a la pluralidad y el cambio permanente que confunde los sentidos, existe una estabilidad global a la que se accede por la razón ${ }^{19}$. Ante la diversidad de las apariencias, es necesario descubrir la unidad. Los principios que rigen el cambio y el movimiento no son otros que los principios de simpatía-antipatía investidos de

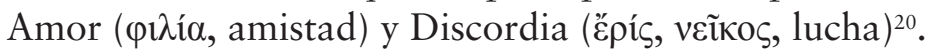

Coincidiendo con los pitagóricos, la interpretación de la naturaleza por opuestos de Heráclito, reconoce "una analogía o equivalencia" entre las parejas de opuestos. El principio de que los opuestos son "uno" y "el mismo" es uno de los rasgos que caracterizan su filosofía ${ }^{21}$.

En numerosos tratados del $\mathrm{CH}$ es posible encontrar también una fundamental concepción de la phýsis humana basada en la semejanza y en la afinidad de sus componentes, haciendo patente la relación de la parte al todo. En el tratado Sobre los lugares en el hombre, por ejemplo, se hace referencia a la afinidad y conexión que existe entre la totalidad del cuerpo humano y cada una de sus partes:

El cuerpo en su conjunto es homogéneo en sí mismo y formado por los mismos elementos, que, sin embargo, no tienen la misma disposición entre sí, según se trate de los grandes o los pequeños, los de arriba o los de abajo. Así, si alguien intenta, cogiendo la parte más pequeña del cuerpo, provocar un daño, todo el cuerpo se re-

${ }^{18}$ Kirk-Raven (1987), p. 409.

${ }^{19}$ Lloyd (1987), pp. 95 y ss.

20 Se trata de "fuerzas morales y psicológicas expresadas en términos corpóreos", Kirk-Raven (1987), p. 509. Empédocles también denomina a sus cuatro elementos con los nombres de dioses, dando a entender que las divinidades son "el reconocimiento de poderes y propiedades, indefinidos hasta ese momento”, Kirk-Raven (1987), p. 408-9.

${ }^{21}$ Lloyd (1987), pp. 96 y 98. "No escuchándome a mí, sino a la razón, sabio es reconocer que todas las cosas son una”. DK 22 [12] в 50 [1], p. 161; Kirk-Raven (1987), 196, p. 273; Bernabé (2008), 26 [50], p. 132. 
sentirá de este mal, cualquiera que sea. La razón es la siguiente: la parte más pequeña del cuerpo posee todo lo que también posee la más grande. Lo que padece, sea lo que sea, lo transmite la parte más pequeña a todo lo que tiene su misma naturaleza y su mismo origen, tanto si es bueno, como si es malo. Y la razón por la que todo el cuerpo sufre dolores y placeres a causa del elemento más pequeño es que en este elemento más pequeño están todos los componentes del cuerpo y ellos les transmiten las sensaciones a cada uno de sus iguales y les comunican todo. ${ }^{22}$

Esta relación de afinidad entre la parte y el todo define, en gran medida, la interpretación hipocrática de la phýsis humana. En ella la idea de simpatía resulta esencial, por la necesidad de establecer correlaciones de semejanza e identidad entre los elementos que componen el todo. El carácter del concepto de la phýsis humana radica en la articulación permanente entre la parte y el todo. El verdadero médico "nunca desliga la parte del todo, sino que la enfoca siempre en sus relaciones de interdependencia con el conjunto" ${ }^{23}$. En el Fedro, Platón sostiene a este respecto que la medicina hipocrática se caracterizaría por su "concepción organicista de la naturaleza". Esto es, por comprender "la función de la parte dentro del todo, determinando así lo más adecuado para el tratamiento de la parte" ${ }^{24}$.

Afirmo que quien pretende componer acertadamente un escrito sobre la dieta humana debe, antes que nada, reconocer y discernir la naturaleza del hombre en general; conocer de qué partes está compuesto desde su origen y distinguir de qué elementos está dominado. Pues si no reconoce la composición fundamental, será incapaz de conocer lo que de ella se deriva. Y si no discierne qué es lo dominante en el cuerpo, no será capaz de procurarle lo conveniente al ser humano. ${ }^{25}$

Tal concepción organicista de la naturaleza (organicismo cósmico) tuvo su expresión filosófica más acabada en el Timeo, donde Platón expone la idea del cosmos como un animal cuyas partes están armónicamente relacionadas.

Antecedentes de esta idea, no obstante, pueden encontrarse en Empédocles y Anaxágoras. La interpretación que ambos realizan de la biológica de la naturaleza, les sitúa entre los primeros organicistas y, por tanto, entre los promotores iniciales de la analogía cósmica, de acuerdo con la cual entre el macrocosmos (cosmos) y el microcosmos (hombre) existen relaciones de

22 "Sobre los lugares en el hombre”, Hipócrates (2003), pp. 90-91; Loc. Hom. (Littré VI, 1-2, p. 279).

${ }^{23}$ Jaeger (1990), p. 809.

${ }^{24}$ Ibíd. Platón habla elogiosamente del método utilizado por Hipócrates en Fedro (270 c-d) y también en el Protágoras. Sobre la explicación por articulación de partes en biología ver Kauffman (1998).

25 “Sobre la dieta”, Hipócrates (1986), p. 21; Vict. [iv] Insomn (Littré VI, p. 469). 
comunidad y afinidad. Según esta analogía, siguiendo el principio de la relación de la parte al todo, los mismos elementos que forman el cosmos y la naturaleza, son constitutivos del hombre ${ }^{26}$.

El fundamento de esta analogía cósmica es la idea de simpatía universal entre los elementos que constituyen la phýsis como un todo. Según Alcmeón de Crotona, y el propio Empédocles, los procesos del mundo orgánico y del cosmos son idénticos ${ }^{27}$. La influencia de ambos en el pensamiento hipocrático se percibe en numerosos tratados ${ }^{28}$, principalmente en los que hablan de los humores que componen el organismo humano:

El cuerpo del hombre alberga siempre estos mismos elementos, pero con los ciclos de las estaciones unas veces aumentan y otras disminuyen, sucesivamente y según su naturaleza. Así, al igual que el año entero participa de todos los elementos: de lo caliente, de lo frío, de lo seco y de lo húmedo -y nada podría subsistir un solo instante sin todos los elementos que componen el orden del mundo [cosmos], y si faltara uno, todo desaparecería, ya que todos los seres se constituyen y se nutren mutuamente en virtud de una misma ley-, del mismo modo, si le faltara al hombre alguno de sus elementos congénitos, no le sería posible la existencia. ${ }^{29}$

Insertos en esta relación de la parte al todo, se encuentran los vínculos de simpatía que permiten explicar las maneras en que un órgano ${ }^{30}$ enfermo puede afectar a otro órgano o al conjunto del cuerpo ${ }^{31}$. Algunas afecciones, como el dolor de cabeza desencadenado por un malestar intestinal o la indisposición orgánica que se expresa como dolencia gástrica, fueron los casos más reconocidos. Tales afecciones se explican en algunos tratados del $\mathrm{CH}$ por las relaciones de simpatía o afinidad:

Todas las partes del cuerpo, cuando la enfermedad se mueve bien a un punto, bien a otro, se la transmiten inmediatamente de una a otra: el vientre a la cabeza, la cabeza a las masas de carne y al vientre, y todo lo demás según este mismo principio. ${ }^{32}$

En virtud de tales vínculos de afinidad fue posible concebir un principio etiológico útil para el diagnóstico y el tratamiento de numerosas enfermedades. Después de todo, sería de vital importancia reconocer que, en

\footnotetext{
${ }^{26}$ Para Demócrito “el hombre es un mundo en pequeño" (DK 68 [55] в 34, 5-10, p.153). Laín Entralgo (1982), p. 124.

${ }^{27}$ Bernabé (2008), p. 191.

${ }^{28}$ La teoría de los humores, con la que se identifica a la medicina hipocrática, es una transposición de los cuatro elementos de Empédocles. Asimismo, la idea de salud de Alcmeón encarna la concepción de salud hipocrática. Ver Jouanna (1961).

29 “Sobre la naturaleza del hombre”, Hipócrates (2003), pp. 44-46; Nat. Hom. (Littré VI, 7-8. pp. 49-51 y 53). Otras expresiones de la analogía cósmica se encuentran en "Sobre la dieta IV", Hipócrates (1986); Vict. [iv] Insomn. (Littré VI, pp. 466-662) y en "Sobre las semanas”, Hipócrates (2003); Hebd. (Littré VIII, pp. 634-673).
} 
muchas ocasiones, la causa de una dolencia no se encuentra en el órgano visiblemente afectado, sino que proviene de un lugar oculto o de una causa que escapa a la observación directa:

En consecuencia, la mejor forma de tratar las partes enfermas es a través de las que se las provocan, pues es así como mejor se puede curar la causa de la enfermedad. ${ }^{33}$

Esta "ley" de afinidad, empero, no es indiscriminada o aleatoria, ni establecida por capricho. Como subraya Littré, la simpatía se establecería bajo tres condiciones principales: contigüidad, analogía de estructura y conformidad de la acción ${ }^{34}$. Ello implica la puesta en juego de cualidades extraordinarias de observación de la fisiología anatómica humana y animal, y una concepción elaborada del pensamiento por analogía. Las condiciones de comunidad, simpatía y conexión funcional han de ser las convenientes, ya que "entre las distintas partes del cuerpo hay comunidades, simpatías o conexiones... en cuya virtud se mantiene anatómica y funcionalmente su unidad orgánica" ${ }^{35}$. Así se expresa, por ejemplo, en Epidemias VI:

Los lugares que reciben desde otro lugar resuelven la afección mediante dolor, sensación de pesadez o de alguna otra cosa, pero (solo) aquellos entre los que hay conexión. ${ }^{36}$

${ }^{30}$ Sobre la fisiología del órgano como recipiente ver Ioannidi (1983).

${ }^{31}$ A este tipo de afecciones, Galeno las denominará “afecciones simpáticas”. Galeno es el primero en utilizar la noción de simpatía de manera sistemática como concepto diagnóstico. La simpatía, desde su punto de vista, es la influencia mediante la cual dos partes distintas del cuerpo llegan a estar implicadas, simultánea o sucesivamente, en el transcurso de una enfermedad (Siegel 1968, pp. 361-362). Si bien dice suscribir el todo en simpatía del pensamiento hipocrático, se trata de un anacronismo cometido por Galeno para favorecer su doctrina (Holmes 2014, p. 125). En realidad fueron los estoicos, muy influyentes en el pensamiento de Galeno, quienes sistematizaron la idea de simpatía universal, dándole una dimensión ética y epistemológica nunca antes alcanzada. Aunque la influencia estoica se deja ver en algunos tratados del $\mathrm{CH}$ de la última época, la cuestión de la simpatía en el estoicismo requiere, por su extensión, un trabajo aparte.

32 "Sobre los lugares en el hombre”, Hipócrates (2003), p. 89; Loc. Hom. (Littré VI, 1, p. 277).

33 “Sobre los lugares en el hombre", Hipócrates (2003), p. 90; Loc. Hom. (Littré VI, 1, p. 279).

${ }^{34}$ Littré III, 1, pp. 25-27.

${ }^{35}$ Laín Entralgo (1982), p. 168. En palabras de Heráclito: “Conexiones, totalidades-no totalidades: convergente-divergente, consonante-disonante..., de todas las cosas, una sola, y de una sola todas”, DK 22 [12] в 10 [59], pp. 152-153; Kirk-Raven (1987), 203, p. 277; Bernabé (2008), 25 [10], p. 132.

36 “Epidemias VI”, Hipócrates (1989), p. 226; Epid. (Littré V, 3, 23, p. 305 ). 


\section{Principio de lo igual hacia lo igual}

Las relaciones de simpatía entre las distintas partes del cuerpo humano, son un caso especial de las relaciones de semejanza (por homología o analogía), establecidas para explicar procesos complejos de funcionamiento y de causalidad en la phýsis humana ${ }^{37}$. Procesos como el desarrollo embrionario, la nutrición o la enfermedad se describieron a menudo con alguna variante de la polaridad simpatía-antipatía, siguiendo la denominada doctrina de atracción de los semejantes. Dicha doctrina, que regularía la phýsis en general y que es tenida en cuenta por la mayoría de los físicos griegos, se rige por el principio de lo igual hacia lo igual, determinante no solo en física, sino también en biología y epistemología, particularmente en la interpretación de los procesos de percepción y aprendizaje ${ }^{38}$. Según Lloyd, esta doctrina se asociaba a una amplia gama de fenómenos naturales como las fuerzas de atracción o el comportamiento gregario de los animales ${ }^{39}$.

Un proceso que ilustra la aplicación de este principio es el de la transmisión de los caracteres hereditarios. En algunos tratados del $\mathrm{CH}$ se dice que tanto la mujer como el hombre generan esperma procedente de todas las partes del cuerpo. El principio de lo igual hacia lo igual permite interpretar las fuerzas reguladoras de agregación y concebir el desarrollo de la gestación del feto, así como su características últimas:

A la matriz llega el esperma de la mujer y del hombre desde todo el cuerpo, débil desde las partes débiles y fuerte desde las partes fuertes; y necesariamente se transmite con estas características al hijo. Y si desde cualquier parte del cuerpo del hombre se aporta más cantidad al esperma que desde la mujer, el hijo se parece más al padre; pero si se aporta más desde cualquier parte del cuerpo de la mujer, entonces el hijo se parece más a la madre. No es posible parecerse en todo a la madre y en nada al padre, ni lo contrario, ni tampoco no parecerse en nada a ninguno de los dos. ${ }^{40}$

En aras del mismo principio, el autor de Sobre la naturaleza del niño expone su teoría embriológica y su descripción del desarrollo de los miembros y órganos, recurriendo a la comparación con un árbol:

La carne, al desarrollarse, se articula en miembros por efecto del soplo, y en ella cada elemento se dirige hacia su semejante, lo denso hacia lo denso, lo poroso hacia lo poroso, lo húmedo hacia lo húmedo; cada uno se dirige a su lugar propio de acuerdo con el grado de parentesco del que ha salido; todo lo que procede de elementos

${ }^{37}$ Lloyd (1987), pp. 68 y ss.

${ }^{38}$ Homero invoca este principio cuando hace decir a Ulises: "dios lleva siempre lo igual hacia lo igual (Od., XVII, 218)", Kirk-Raven (1987), p. 584.

${ }^{39}$ Lloyd (2007), p. 134; Kirk-Raven (1987), pp. 583-584, n. 2.

40 "Sobre la generación”, Hipócrates (2003), p. 255; Genit., Nat. Puer., Morb. (Littré VII, 8, p. 481). 
densos, es denso y lo que proviene de elementos húmedos, es húmedo; todo lo demás se forma según el mismo proceso durante el crecimiento. ${ }^{41}$

Con el ánimo de demostrar la legitimidad de su descripción, propone un experimento a continuación. Pese a lo rudimentaria que pueda parecer, su propuesta es un ejemplo del espíritu empírico que alienta al razonamiento médico de la época.

Si se ata una cánula a una vejiga y se introduce en ella a través de la cánula tierra, arena, o pequeñas lascas de plomo y, tras verter agua, se sopla por el tubo, primero todo se habrá mezclado con el agua, pero luego, con el tiempo, debido al aire, el plomo se irá hacia el plomo, la arena hacia la arena y la tierra hacia la tierra. Y si se deja secar y se mira atentamente al abrir la vejiga, se descubrirá que lo semejante va hacia lo semejante. También así la simiente y la carne se articulan, y en ella lo semejante acude a lo semejante. ${ }^{42}$

También el proceso de descomposición se explica de este modo. La disolución de la mezcla que compone el cuerpo, provoca que los elementos opuestos busquen sus iguales en la naturaleza, retornando al lugar del cosmos del que provienen ${ }^{43}$. Esta interpretación tiene su origen en Empédocles y Anaxágoras, quienes suscribían la doctrina parmenídea de que "nada puede llegar a ser a partir de lo que no es" ${ }^{44}$. En respuesta al desafío de explicar el cambio bajo esa premisa, Empédocles representa el nacimiento y la muerte por el par antitético agregación-disolución ${ }^{45}$. Las fuerzas de amor y discordia, antecedentes de los principios de simpatía-antipatía, se suceden cíclicamente y gobiernan la vida animal y la naturaleza entera ${ }^{46}$.

La doctrina de atracción de los semejantes permitió a Empédocles descubrir numerosas analogías, que mostraban el "inesperado parentesco" existente en toda la naturaleza ${ }^{47}$. Gracias a su capacidad de percibir "funciones

41 “Sobre la naturaleza del niño”, Hipócrates (2003), p. 266; Genit., Nat. Puer., Morb. (Littré VII, 17, pp. 497-499).

42 “Sobre la naturaleza del niño", Hipócrates (2003), p. 267; Genit., Nat. Puer., Morb. (Littré VII, 17, p. 499).

43 “Sobre la naturaleza del hombre", Hipócrates (2003), p. 36; Nat. Hom. (Littré VI, 3, p. 39). Cf. Laín Entralgo (1982), p. 167.

44 "Y es que nunca se violará tal cosa, de forma que algo, sin ser, sea”. DK 28 [18] в 7, p. 234; Kirk-Raven (1987), 294, pp. 357-358; Bernabé (2008), 7, p. 157. Para Aristóteles se trataba de un principio generalizado entre los filósofos de la naturaleza (Phys. A 4: 187 a 26-29). Lloyd (1987), p. 104.

${ }^{45}$ Anaxágoras llama composición (combinación) al nacimiento y disolución (separación) a la muerte. Kirk-Raven (1987), p. 502.

${ }^{46}$ DK 31 [21] в 20, pp. 318-319. Bernabé (2008), p. 214.

47 “Sudor de la tierra, el mar." DK 31 [21] в 55, p. 332; Bernabé (2008), p. 217. También Anaxágoras: "Lo que llamamos leche del pájaro es lo blanco del huevo." Kirk-Raven (1987), 504, p. 534; Bernabé (2008), 22, p. 257. 
homólogas en partes claramente disímiles de muy diferentes clases de seres vivos" ${ }^{48}$, el razonamiento por analogía tiene en él a uno de sus más destacados precedentes. Según su sistema, el amor, encargado de establecer los vínculos de simpatía entre los elementos iguales e, incluso, disímiles, prepara la mezcla que constituye todo organismo, promoviendo la atracción entre ellos (DK 31 [21] в 22, pp. 320-321) ${ }^{49}$.

Por otro lado, Empédocles entendía que el fenómeno de la percepción ${ }^{50}$ se produce cuando los efluvios que emanan de los objetos atraviesan los poros de los sentidos. Según esta idea, los seres semejantes poseerían poros y efluvios que les permitirían reconocerse siguiendo el principio de atracción de lo igual hacia lo igual. Fenómenos complejos y difíciles de interpretar como la mezcla química, el magnetismo o el conocimiento ${ }^{51}$, fueron explicados del mismo modo ${ }^{52}$.

Una de las aplicaciones prácticas más destacadas del principio que estamos examinando, tiene su lugar en la interpretación de la nutrición y el crecimiento del niño. Así por ejemplo, en el tratado Sobre las carnes se dice que los alimentos poseen la propiedad de hacer crecer las diferentes partes del cuerpo, según sus cualidades concretas:

Los primeros dientes se le forman al niño gracias a la alimentación recibida en la matriz y, una vez que nace, gracias a la leche que mama. Y cuando caen estos dientes, los otros se forman gracias a la comida y la bebida.

El alimento, cuando llega a cada zona del cuerpo, proporciona a cada cosa la forma que corresponde a lo que es; pues, nutrido por el alimento, todo crece: el calor, el frío, lo viscoso, lo graso, lo dulce, lo amargo, los huesos y todos los demás elementos que hay en el ser humano. ${ }^{53}$

Anaxágoras habría sostenido igualmente, que en los alimentos está todo lo que a partir de ellos se nutre y desarrolla. Es de destacar, sin embargo, que para Anaxágoras la cadena causal entre cosas homogéneas, como la

48 "Una misma cosa son el pelo, las hojas, los espesos plumajes de las aves y las escamas que nacen sobre los pesados miembros.” DK 31 [21] в 82, p. 341; Kirk-Raven (1987), p. 433.

${ }^{49}$ Kirk-Raven (1987), p. 435.

${ }^{50}$ Kirk-Raven (1987), pp. 373-375.

${ }^{51} \mathrm{El}$ conocimiento proviene de las cosas semejantes, mientras que la ignorancia proviene de las diferentes. DK 31 [21] A 86; Kirk-Raven (1987), 392, p. 439.

52 "Pues con la tierra vemos la tierra, con el agua el agua, con el aire el aire brillante y con el fuego el fuego destructor; con el Amor vemos al Amor y a la Discordia con la funesta Discordia.” DK 31 [21] в 109, p. 351; Kirk-Raven (1987), p. 440.

53 "Sobre las carnes", Hipócrates (2003), pp. 157 y 158; Carn. (Littré VIII, 12-13, pp. 599 y 601). 
que existe entre los alimentos y los órganos, no es evidente, sino que ha de percibirse mediante el uso de la razón:

Anaxágoras de Clazomene, hijo de Hegesibulo, sostuvo que los primeros principios de las cosas eran las homeomerías. Pues le parecía imposible que ninguna cosa llegara al ser a partir de lo que no es o que en ello se disolviera. En todo caso, nos alimentamos de lo que es simple y homogéneo, como pan y agua, y con ello se nutren el pelo, las venas, las arterias, la carne, los nervios, los huesos y las demás partes del cuerpo. En consecuencia, hay que reconocer que, en el alimento que tomamos, están todas las cosas y que todo deriva su crecimiento de las cosas que existen. En este alimento debe haber algunas partes productoras de sangre, de nervios y de huesos, etc. -Partes que solo la razón puede contemplar-. Porque no es necesario referir a la percepción de los sentidos el hecho de que el pan y el agua producen todas estas cosas, sino que más bien hay, en el pan y el agua, partes que solo la razón puede contemplar. (DK 59 [46] в 46, p. 18)

La existencia de numerosos tratados dedicados al tema de la nutrición en el $\mathrm{CH}$, pone de relieve que la dieta es el método terapéutico por excelencia, en el que el médico encuentra el mejor recurso para restituir la salud y la armonía perdidas con la enfermedad. Para la medicina hipocrática, el equilibrio humoral y de las partes del cuerpo se mantiene gracias a la participación de dos agentes: el calor (innato o implantado) y el alimento. El calor innato se encuentra localizado en el ventrículo izquierdo del corazón, mientras que el alimento procede del exterior y puede ser sólido, líquido o aéreo $^{55}$.

El alimento llega desde dentro al pelo, las uñas y la última superficie, desde fuera, desde la última superficie a lo más interno. La confluencia es única, la conspiración (sympnoia) es única, todo en simpatía. Todo es según el conjunto, y según la parte son las partes de cada parte en lo relativo a su función. El primer principio llega a la última parte; desde la última parte al primer principio llega el alimento: es una sola naturaleza ser y no ser. ${ }^{56}$

Según Aristóteles, los presocráticos ${ }^{57}$ concebían dos tipos de alimentación, una por "lo contrario" (cuando es opuesta a la naturaleza del hombre), en la que hay que proceder a una "asimilación"; y una alimentación por "lo semejante" (cuando las propiedades nutrientes coinciden con las del

${ }^{54}$ Kirk-Raven (1987), pp. 523-524.

${ }^{55}$ Laín Entralgo (1982), pp. 168-169.

56 “Sobre el alimento", Hipócrates (1986), pp. 253-254; Alim. (Littré IX, 22-24, p. 107). La influencia de Heráclito se hace evidente en la última parte.

57 "Algunos opinan que lo semejante se alimenta y crece con lo semejante, mientras que otros opinan a la inversa..." (De an. 416a 30; cf. 416b 5-10). Aunque Aristóteles no da nombres, es evidente que se está refiriendo a Empédocles y Anaxágoras. Laín Entralgo (1982), pp. 173 y ss. 
cuerpo humano $)^{58}$. De modo análogo, dos leyes dominan la concepción hipocrática de la digestión: la "ley de predominio" y la "ley de asimilación". Según la ley de predominio, solo es digerido aquello cuya dynamis puede ser dominada por la dynamis de los órganos digestivos. De acuerdo con la ley de asimilación, lo semejante va a lo semejante, y su ejecución exige "la «atracción específica» o capacidad de cada parte de atraer hacia sí lo que conviene a su estructura y su función" 59 .

Otro aspecto importante en el que se pone de manifiesto la dialéctica simpatía-antipatía, dentro de la medicina hipocrática, es en las reglas terapéuticas, principalmente en la aplicación curativa del método o tratamiento de los contrarios, que recibirá el nombre de antipatía o alopatía (contraria contrariis curantur -lo contrario se cura por lo contrario-) ${ }^{60}$ :

Las enfermedades que se producen por hartura las remedia una evacuación, y las que provienen de evacuación las soluciona la hartura; también en los demás casos, la oposición de contrarios. ${ }^{61}$

Fundada en la creencia de la acción curadora de lo semejante, la homeopatía (similia similibus curantur -lo semejante se cura por lo semejante-) también encuentra expresión en el $\mathrm{CH}^{62}$. De acuerdo con el principio de lo igual hacia lo igual, aquello que causa la enfermedad debe poseer su remedio. No se trata, empero, de métodos opuestos o independientes. El médico, de forma combinada, hará uso de la alopatía y de la homeopatía según las circunstancias:

La mayoría [de las enfermedades] pueden remediarse mediante esas mismas cosas en las que tienen su origen. Porque una cosa le es alimento a otra, pero en otras ocasiones es su destrucción. Eso, desde luego, debe saberlo el médico, de modo que, distinguiendo el momento oportuno de cada cosa, dé y aumente el alimento en un caso, y se lo disminuya y niegue en otro. Es preciso, pues, tanto en ésta como en las otras enfermedades, no aumentar las dolencias, sino eliminarlas, administrando lo más contrario a la enfermedad en cada caso, y no lo más afín. Pues con lo afín se desarrolla y aumenta, y por efecto de lo contrario se consume y extingue. ${ }^{63}$

58 También en Phys. 260a 25-30 hace referencia a la alimentación por lo semejante.

${ }^{59}$ Laín Entralgo (1982), pp. 174-175 y (1987), p. 103.

60 "Nada al azar, no pasar nada por alto. Gradualmente aplicar cosas contrarias y hacer pausas”, “Epidemias VI”, Hipócrates (1989), p. 218; Epid. (Littré V, 2, 12, p. 285). Ver "Sobre los flatos", Hipócrates (1986), pp. 132-133; Flat. (Littré VI, 1, p. 93).

61 “Aforismos", Hipócrates (1983), p. 252; Aph. (Littré II, 22, p. 477).

${ }^{62}$ Laín Entralgo (1987), pp. 312-313.

63 "Sobre la enfermedad sagrada", Hipócrates (1983), p. 420; Morb. Sacr. (Littré VI, 18, pp. 395-397). En otro lugar se recomienda actuar según los resultados: "Siempre hay que abandonar el procedimiento que no produzca curación; y si hace que algo empeore, hay que irse a lo contrario. Pero si impulsa la curación, en absoluto hay que retirar nada de lo 
Sea cual sea el método utilizado, lo importante es que se tengan en cuenta las leyes de afinidad para poder mantener el equilibrio de los humores y proceder al tratamiento, en presencia de enfermedad.

Siguiendo el mismo principio, en el tratado Sobre la naturaleza del hombre se defiende la utilidad de determinados fármacos que, en virtud de su capacidad de atraer los humores correspondientes a su propia naturaleza, permiten su segregación y expulsión. Con ello el autor pretende refutar, si bien de una manera ingenuamente empírica, la interpretación de la naturaleza y el tratamiento de las enfermedades por la serie de opuestos aire, fuego, agua y tierra que proponían los filósofos:

Pues cuando el fármaco entra en el cuerpo, primero atrae aquel elemento del cuerpo más semejante a su naturaleza, después segrega y purga los demás. Al igual que los vegetales que brotan o se siembran, cuando entran en la tierra, absorben aquel elemento de ella más conforme a su naturaleza (éstos son lo ácido, lo amargo, lo dulce, lo salado y todo lo demás); es decir, extraen primero de la tierra la mayor cantidad del elemento más semejante a su naturaleza y después el resto; así también actúan los fármacos en el cuerpo: los que producen la segregación de bilis, producen en primer lugar una bilis absolutamente pura, y a continuación una ya mezclada ${ }^{64}$

La atracción específica que permite la asimilación de los alimentos y los humores que les son propios, encuentra en el estómago su fuente principal. Cuando está lleno, el cuerpo toma de él los humores que necesita para mantener la salud. En cambio, si está vacío tiene que recurrir a otras fuentes: la sangre se extrae del corazón, la flema de la cabeza, el agua del bazo y la bilis del hígado. Dicha atracción y absorción se llevan a cabo cumpliendo el principio de lo semejante hacia lo semejante:

Cuando alguien come o bebe, el cuerpo arrastra hacia sí desde el vientre el humor en cuestión y las fuentes lo arrastran desde el vientre a través de las venas; cada variedad de humor arrastra a su semejante y lo distribuye en el cuerpo, lo mismo que en el caso de las plantas cada clase de humor arrastra de la tierra a su semejante. ${ }^{65}$

aplicado, ni interrumpir el tratamiento, ni añadir ninguna otra cosa." "Sobre los lugares en el hombre”, Hipócrates (2003), p. 103; Loc. Hom. (Littré VI, 12, p. 299). Ver también Op. cit., p. 127; Loc. Hom. (Littré VI, 42, p. 335).

64 "Sobre la naturaleza del hombre", Hipócrates (2003), p. 41; Nat. Hom. (Littré VI, 6, pp. 45-47).

65 "Sobre las enfermedades IV", Hipócrates (2003), p. 295; Genit., Nat. Puer., Morb. (Littré VII, 33, p. 545). Ver "Sobre los humores", Hipócrates (1986), pp. 110-111; Hum. (Littré V, 11, pp. 491-493). 


\section{Isonomía y monarquía}

El propósito de restaurar o mantener el equilibrio humoral es uno de los fundamentos de la práctica médica hipocrática. En dicha práctica, que considera la biología humana en continuo movimiento, las relaciones de armonía y de comunidad de los órganos son esenciales. Cumpliendo con este criterio, la salud es definida como el equilibrio (isonomía) en la mezcla de los humores, mientras que se considera que la enfermedad se produce ante el predominio de uno solo de ellos (monarchía),

Todas las causas de los males nos llevan a lo mismo: los elementos excesivamente fuertes y dominantes dañan al hombre, tanto al que está sano como al que está enfermo. ${ }^{66}$

La fuente de este ideal de equilibrio se encuentra en la mezcla armónica de los opuestos, que los filósofos de la naturaleza concibieron como origen del cosmos. Influido por la escuela médica de Crotona, Parménides, al igual que Empédocles y Heráclito, consideró el orden de la naturaleza como resultado de la interacción y la harmonía de fuerzas opuestas ${ }^{67}$. Esta mezcla y proporción de los opuestos en la cosmología, coincide precisamente con la idea de salud defendida por Alcmeón de Crotona:

... la mantenedora de la salud es la "igual distribución” de las fuerzas, de lo húmedo y de lo seco, de lo frío y de lo caliente, de lo amargo y de lo dulce y de las demás, mientras que la supremacía de una de ellas es destructiva. La enfermedad sobreviene directamente por el exceso del calor o del frío, indirectamente por exceso o deficiencia de nutrición; y su centro son bien la sangre, la médula o el cerebro. Surge, a veces, en estos centros, desde causas externas, de ciertas humedades, del ambiente, del agotamiento, de la privación o de causas semejantes. La salud, por otra parte, es la mezcla proporcionada de las cualidades. (DK 24 [14] в 4 [22], p. 215) ${ }^{68}$

El equilibrio tiene su fundamento en la idea misma de cosmos, así como en la concepción orgánica de la phýsis. Ahora bien, si los filósofos de la naturaleza concibieron el cosmos como una "comunidad de las cosas, sujetas a orden y justicia", como advierte Jaeger, fue porque "se sirvieron del orden de la existencia humana para pensar la phýsis y su interpretación" ${ }^{69}$. Expresión de ello es la norma de justicia que Anaximandro formula sobre la causalidad cósmica:

66 "Sobre la medicina antigua”, Hipócrates (1983), p. 144; VM (Littré I, 6-7, p. 585).

${ }^{67}$ Kirk-Raven (1987), p. 373.

${ }^{68}$ Kirk-Raven (1987), pp. 372-373.

${ }^{69}$ Jaeger (1990), p. 160. 
El principio de los seres es indefinido... y las cosas perecen en lo mismo que les dio el ser, según la necesidad. Y es que se dan mutuamente justa retribución por su injusticia, según la disposición del tiempo. (DK 12 [2] A 9, p. 83)

Según esta sentencia, todo en la phýsis se rige bajo una norma de compensación. La idea de justicia del mundo que de ella se desprende, posee un

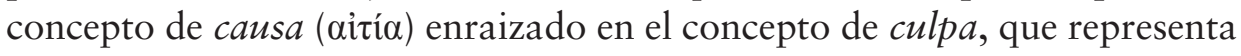
un paso "de la imputación jurídica a la causalidad física"71.

Si el dolor y la enfermedad tienen lugar cuando se rompe el equilibrio de las fuerzas opuestas presentes en la phýsis humana, la medicina tiene una norma de compensación que consiste en indemnizar o reparar (isomoira) la harmonía natural propia de la salud ${ }^{72}$.

Se produce dolor tanto por causa del frío como del calor, tanto por el exceso de ellos como por el defecto. En las partes del cuerpo que son frías por naturaleza, en las que están en la parte externa del cuerpo, junto a la piel, se produce dolor a causa de lo que está demasiado caliente y en las partes calientes por naturaleza, a causa de lo que está frío. En las partes que son secas por naturaleza, cuando reciben humedad y en las que son húmedas por naturaleza, cuando se secan. Porque los dolores se producen en todas las cosas que ven su naturaleza alterada y destruida. ${ }^{73}$

La acción sanadora del médico consistirá entonces en "restaurar la medida oculta" alterada por la enfermedad ${ }^{74}$. Dicha acción, sin embargo, consiste fundamentalmente en ayudar a la naturaleza, pues según la concepción teleológica hipocrática ${ }^{75}$, ella por sí sola acude a restablecer la armonía y equilibrio perdidos. El proceso mismo de enfermar, se considera un esfuerzo de la phýsis por restablecer la debida proporción de los opuestos. El médico, por tanto, debe ayudar a la naturaleza en su tarea de restablecer el orden de las cosas, más que intervenir en su contra ${ }^{76}$.

${ }^{70}$ Bernabé (2008), p. 56. “Anaximandro explica el constante intercambio entre sustancias opuestas mediante una metáfora legalista, tomada de la sociedad humana. (...) la continuidad y estabilidad del cambio natural recibió su impulso de esta metáfora antropomórfica.” KirkRaven (1987), p. 180.

71 "Su diké es el principio del proceso de proyección de la polis al universo." Jaeger (1990), p. 160.

${ }^{72}$ Jaeger (1990), pp. 786-787.

73 "Sobre los lugares en el hombre", Hipócrates (2003), pp. 125-126; Loc. Hom. (Littré VI, 42, p. 335).

${ }^{74}$ Jaeger (1990), pp. 809-810.

75 Jaeger (1990), p. 810.

${ }^{76}$ Jaeger (1990), pp. 810-811. 


\section{Razonamiento por oposición y semejanza}

En la medida en que la salud se concibió como un equilibrio y la enfermedad como un desequilibrio, la medicina hipocrática utilizó ampliamente los métodos de razonamiento por oposición y semejanza. La necesidad de alcanzar el mayor grado de certeza posible ${ }^{77}$ en la comprensión de las enfermedades y en los pronósticos, condujo a la medicina a desarrollar formas de conocimiento probable, basadas principalmente en la analogía y en el reconocimiento de los signos $(\varepsilon \tilde{i} \delta o \varsigma)^{78}$. Transferir certeza de lo conocido a lo menos conocido fue una cuestión decisiva en el campo médico, mucho antes de que se consolidara el método demostrativo aristotélico.

Este aspecto de la epistemología médica hipocrática podría enmarcarse en el llamado "problema de la evidencia"79, que demanda la justificación de inferir la existencia de algo por una observación dada, o más exactamente, la justificación de inferir una cosa no observada por la existencia de otra observada. Esta necesidad de formular un diagnóstico tendría una forma muy elemental de abducción, en tanto que va desde los efectos a las causas, es decir, "de los síntomas y signos que presenta un paciente, a los posibles síndromes y patologías que se manifiestan a través de ellos" ${ }^{80}$. Si tenemos en cuenta que la abducción prevalece en el curso de la observación de "hechos novedosos y anómalos" $" 1$, hemos de considerarla un instrumento de razonamiento eficaz en el contexto médico y, quizá en mayor medida, en el ámbito de la medicina hipocrática ${ }^{82}$.

En el orden del razonamiento abductivo, la polaridad simpatía-antipatía formaría parte de las "reglas" o "estereotipos" aprendidos por el médico durante su formación ${ }^{83}$. Tales reglas ayudarían a interpretar fenóme-

77 Jaeger (1990), p. 801.

78 "Para los griegos, la observación clínica era la base de la practica medica; bien realizada, debía permitir recabar todos los síntomas, signos y cambios en la condición del paciente durante el curso de su enfermedad. Una buena clínica conducía a: 1) un diagnostico acertado; en este sentido se preguntaban de qué manera el enfermo difería de lo normal; 2) un pronóstico adecuado, que se hacía pensando en otros pacientes con cuadros semejantes, y 3) un tratamiento oportuno que dependía de la certeza del pronóstico en otros enfermos." Rodríguez de Romo et al (2008), p. 138.

${ }^{79}$ Guillaumin (2005), p. 18.

${ }^{80}$ Rodríguez de Romo et al (2008), p. 144.

${ }^{81}$ Rodríguez de Romo et al (2008), p. 147. Ver también Duarte Calvo (2018), pp. 30-31.

${ }^{82}$ Como señala Fleck (1986), p. 39, el médico es quien estudia "lo atípico, lo anormal, los fenómenos mórbidos”.

83 "Ideas preconcebidas de afinidad", Lloyd (1987), p. 62. Ver también Niño (2001), p. 70. Según la terminología de Peirce, "Regla" es la premisa mayor, de las tres proposiciones que forman el silogismo abductivo. 
nos complejos como las enfermedades, con una sencilla clasificación polar. Simpatía-antipatía conforman un marco conceptual o, mejor, un horizonte de creencias que posibilitan una comprensión y una determinada acción terapéutica. Dicha polaridad se rige generalmente, como hemos visto, por los principios de la parte al todo y de lo igual hacia lo igual.

La utilización de la analogía y el reconocimiento de los signos incluía tres de las dificultades fundamentales relacionadas con el diagnóstico y la curación: establecer los criterios de una observación adecuada, determinar la fuerza de la inferencia y desarrollar una idea de prueba empírica ${ }^{84}$ estrechamente ligada a la experiencia clínica.

Ante el hecho forzoso de que la mayoría de los fenómenos acaecidos en su disciplina eran inobservables ${ }^{85}$ y solo deducibles por la aparición de señales o síntomas, la medicina se vio en la necesidad de recurrir a nociones iniciales de evidencia empírica ${ }^{86}$. Por otra parte, el uso de métodos alternativos de razonamiento permitió establecer principios etiológicos y tratamientos a seguir en las enfermedades. La inferencia a partir de signos permitía hacer acopio de un conjunto de señales, suficientes para alcanzar conclusiones que podían ir desde la mera probabilidad hasta el conocimiento seguro ${ }^{87}$. Dicha inferencia se expresaba frecuentemente refiriéndose a las relaciones entre lo manifiesto y lo oculto, lo visible y lo invisible, etc. ${ }^{88}$

Si bien el concepto de simpatía quedó asociado a lo que posteriormente se denominó “causas ocultas”, para la medicina hipocrática el fundamento de este procedimiento no es adivinatorio ni mágico, sino que intenta ser una interpretación naturalista de los hechos y las posibles relaciones de afinidad entre los elementos. Se trataba, en última instancia, de utilizar el conocimiento

${ }^{84}$ Guillaumin (2005), p. 23.

85 "Existen dos clases de enfermedades: unas que se presentan en lugar bien visible y que no son muchas, y las otras, que están en lo no aparente y que son numerosas." "Sobre la ciencia médica”, Hipócrates (1983), p. 117; Art. (Littré VI, 9, p. 17).

86 “Sobre la medicina antigua”, Hipócrates (1983), p. 138; VM (Littré I, 1, pp. 571-573). Ver Lloyd (1987), p. 72 y Guillaumin (2005), pp. 32-33. Ver también Rodríguez de Romo et al (2008), p. 157.

${ }^{87}$ Guillaumin (2005), p. 68.

${ }^{88} \mathrm{En}$ el $\mathrm{CH}$ se habla reiteradamente acerca de la necesidad investigar lo oculto a través de lo manifiesto. Allen (2001), p. 2. Es evidente la influencia de Heráclito, para quien "La verdadera naturaleza gusta de ocultarse", DK 22 [12] в 123 [10], p. 178; Kirk-Raven (1987), 208, p. 280; Bernabé (2008), 8 [123], p. 130; y es la "Ensambladura invisible, más fuerte que la visible" DK 22 [12] в 54 [47], p. 162; Kirk-Raven (1987), 207, p. 280; Bernabé (2008), 9 [54], p. 130. Anaxágoras expresa claramente esta intuición cuando advierte que "las apariencias son una visión de las cosas oscuras". DK 59 [46] в 21a, p. 43; Kirk-Raven (1987), p. 535. 
de los hechos naturales (observados) para explicar otros hechos naturales $(\text { no observados })^{89}$.

El valor probatorio de las analogías, particularmente en las enfermedades cuyas causas escapaban a la observación, radicaba en la posibilidad de deducir lo invisible de los hechos visibles, en virtud de la correcta interpretación de los signos. Sin el uso del razonamiento, sin la confianza en el logos habría sido imposible conocer lo que no puede ser percibido por medio de los sentidos, es decir, la mayor parte de las causas de las enfermedades ${ }^{90}$. En última instancia, la razón es el único medio de acceder a lo que no puede ser observado:

El caso es que las enfermedades que escapan al examen de los ojos quedan sometidas al examen de la inteligencia. ${ }^{91}$

Aunque se produjeron errores en la aplicación de las relaciones de semejanza y de oposición ${ }^{92}$, el método prosiguió su desarrollo apoyado en la experiencia clínica. La prioridad de curar, que desde el principio dominó la técnica médica, sirvió en gran medida para evitar hipótesis inútiles e inferencias equivocadas ${ }^{93}$. Fueron este tipo de hipótesis y especulaciones teóricas imposibles de verificar, lo que llevó a la medicina a independizarse finalmente de la filosofía ${ }^{94}$.

Con el recurso a las relaciones de simpatía, como intuición primitiva de la afinidad y de la semejanza, la analogía consiguió transformase en paradigma de la racionalidad empírica. Siguiendo sus propios métodos de razonamiento, el pensamiento médico pronto se percataría de que lo habitual en ciencia es hacer inferencias de casos particulares a casos particulares, mucho más que llegar a conclusiones a partir de proposiciones generales ${ }^{95}$.

La utilización de la analogía en la medicina hipocrática, supuso la transformación de una intuición cualitativa (fundamentalmente de carácter antropomórfica), en un principio cuantitativo como, por ejemplo, el concepto moderno de afinidad química, de importantes efectos en la farmacología. La evolución del par antitético simpatía-antipatía, desde el pensamiento primitivo a la cosmología presocrática y a la medicina hipocrática posterior, es una parte importante de este desarrollo.

\footnotetext{
${ }^{89}$ Guillaumin (2005), p. 72; Lloyd (1987), p. 69.

${ }^{90}$ Guillaumin (2005), pp. 78-81.

91 “Sobre la ciencia médica”, Hipócrates (1983), p. 119; Art. (Littré VI, 11, p. 21).

${ }_{92}$ Lloyd (1987), p. 14; pp. 53-68.

${ }_{93}$ Jaeger (1990), p. 799. Peirce distingue la abducción como "el razonar hacia una hipótesis del razonar desde una hipótesis”, Beuchot (1998), p. 57.

94 "Sobre la medicina antigua”, Hipócrates (1983); VM (Littré I, pp. 557-637).
} 
En última instancia, el recurso hipocrático a las relaciones de simpatíaantipatía fue el procedimiento epistemológico más socorrido y más a mano con el que se encontró el pensamiento médico. Al igual que las palabras del médico fueron en muchos casos el remedio más eficaz, por ser el único, también este razonamiento de sentido común se transformó en instrumento epistemológico por ser la única herramienta cognitiva con que se podía contar. Un hábito de razonamiento cotidiano, como el de interpretar lo desconocido por lo conocido, se transformó de este modo en un instrumento de razonamiento empírico ${ }^{96}$.

\section{Conclusión}

El principio de simpatía-antipatía, o de atracción-repulsión, si bien parte de una representación moral y psicológica de las fuerzas de agregación y separación existentes en la naturaleza, es un elemento de transición en el camino que se inicia desde una concepción mítica de la naturaleza hasta una concepción filosófica y lógica. Tales principios organizadores suponen un proceso de conversión hacia una visión naturalista de los fenómenos físicos. Aunque poseen un innegable sustrato antropomórfico, permiten explicar los hechos de la naturaleza desde sí mismos, es decir, remitiendo las causas al propio orden natural. En última instancia, se trata de símbolos útiles y maleables que habrían de desaparecer o modificarse con el surgimiento de la lógica. Esto nos muestra, además, que la forma "personalista" de tales principios organizadores no fue, como se piensa, esencialmente irracional. Al contrario, su establecimiento supone un complejo y avanzado modo de ordenación ${ }^{97}$.

${ }^{95}$ Lloyd (1987), pp. 165-166.

96 "El saber y el conocer son productos de la costumbre. Por tanto, cuando salimos de nuestra costumbre habitual, perece nuestra inteligencia." "Sobre los flatos", Hipócrates (1986), p. 146; Flat. (Littré VI, 14, p. 113).

${ }^{97}$ Kirk-Raven (1987), pp. 114-116. El paso del mitos al logos, como señala Kirk-Raven, no es un simple proceso de despersonalización o desmitificación. Es algo más radical que "una mutación cuasi-mística de los modos de pensar". Pero reducir este cambio decisivo a movimientos político-sociales y religiosos, tampoco sirve para explicarlo. Numerosos experimentos sociales llevados a cabo por la humanidad, nos demuestran que los cambios ambientales no suelen producir este tipo de mutaciones ni a corto ni a largo plazo. Se trata, de cualquier modo, de una transformación psicológica fundamental que debería ser investigada probablemente con otros instrumentos teóricos. 


\section{Bibliografía}

Albarracín Teulón, Agustín (1970), Homero y la medicina, Madrid, Editorial Prensa Española.

Allen, James (2001), Inference from signs. Ancient debates about the nature of evidence, Oxford, University Press.

Bernabé, Alberto (2008), Fragmentos presocráticos de Tales a Demócrito, Madrid, Alianza Editorial.

Beuchot, Mauricio (1998), “Analogía y abducción”, en Analogía Filosófica: revista de filosofía, investigación y difusión XII/1, (1998), pp. 57-68.

Diels, Hermann; Kranz, Walther (1969), Die Fragmente der Vorsokratiker, Dublin, Weidmann.

Duarte Calvo (2018), “Abducción y logica docens", en Revista de Filosofía 43 (1), pp. 27-47.

Estany, Anna e Izquierdo, Merce (1990), "La evolución del concepto de afinidad analizada desde el modelo de S. Toulmin", en Llull, vol. 13, pp. 349-378.

Fleck, Ludwik (1986a), "Some specific features of the medical way of thinking [1927]", in Cohen, R. and Schnelle, T. (ed.), Cognition and fact. Materials on Ludwik Fleck, Boston studies in the philosophy of science, v. 87, Dordrecht, Holland, D Reidel Publishing Company, pp. 39-46. https://doi.org/10.1007/978-94-009-4498-5_2

Fleck, Ludwik (1986b), La génesis y el desarrollo de un becho científico. Introducción a la teoría del estilo de pensamiento y del colectivo de pensamiento, Madrid, Editorial Alianza.

Foucault, Michel (1981), Las palabras y las cosas. Una arqueología de las ciencias humanas, México, Editorial Fondo de Cultura Económica.

Gil, Luis (2004), Therapeia. La medicina popular en el mundo clásico, Madrid, Editorial Triacastela.

Guillaumin, Godfrey (2005), El surgimiento de la noción de evidencia. Un estudio de epistemología histórica sobre la idea de evidencia científica, México, Universidad Nacional Autónoma de México.

Hipócrates (1983), "Sobre la ciencia médica", Tratados hipocráticos I, Madrid, Editorial Gredos, pp. 108-122.

Hipócrates (1983), "Sobre la medicina antigua”, Tratados hipocráticos I, Madrid, Editorial Gredos, pp. 135-167.

Hipócrates (1983), “Aforismos”, Tratados hipocráticos I, Madrid, Editorial Gredos, pp. 243-297.

Hipócrates (1983), “Sobre la enfermedad sagrada”, Tratados hipocráticos I, Madrid, Editorial Gredos, pp. 398-421. 
Hipócrates (1986), “Sobre los humores”, Tratados hipocráticos II, Madrid, Editorial Gredos, pp. 98-117.

Hipócrates (1986), "Sobre los flatos”, Tratados hipocráticos II, Madrid, Editorial Gredos, pp. 131-148.

Hipócrates (1986), "Sobre la dieta", Tratados hipocráticos III, Madrid, Editorial Gredos, pp. 18-116.

Hipócrates (1986), “Sobre el alimento”, Tratados hipocráticos III, Madrid, Editorial Gredos, pp. 248-261.

Hipócrates (1989), "Epidemias", Tratados bipocráticos V, Madrid, Editorial Gredos.

Hipócrates (2003), "Sobre la naturaleza del hombre”, Tratados hipocráticos VIII, Madrid, Editorial Gredos, pp. 29-63.

Hipócrates (2003), "Sobre los lugares en el hombre”, Tratados hipocráticos VIII, Madrid, Editorial Gredos, pp. 89-136.

Hipócrates (2003), “Sobre las carnes”, Tratados hipocráticos VIII, Madrid, Editorial Gredos, pp. 148-164.

Hipócrates (2003), "Sobre la generación”, Tratados hipocráticos VIII, Madrid, Editorial Gredos, pp. 247-257.

Hipócrates (2003), "Sobre la naturaleza del niño", Tratados hipocráticos VIII, Madrid, Editorial Gredos, pp. 258-291.

Hipócrates (2003), "Sobre las enfermedades IV", Tratados hipocráticos VIII, Madrid, Editorial Gredos, pp. 292-341.

Hipócrates (2003), "Sobre las semanas", Tratados hipocráticos VIII, Madrid, Editorial Gredos, pp. 477-529.

Holmes, Brooke (2014), "Proto-symphaty in the Hippocratic Corpus", in Jouanna, J. \& Zink, M. (eds.), Hippocrate et les hippocratismes: médecine, religion, societé. XIVe Colloque International Hippocratique, Paris, Ed. Académie des Inscriptions et Belles-Lettres, pp. 123-138.

Ioannidi, Hélène (1983), "Les notions de partie du corps et d'organe" in Lasserre, F. \& Mudry, Ph. (eds.), Formes del pensée dans la collection hippocratique, Actes $\mathrm{du} \mathrm{IV}^{\mathrm{o}}$ Colloque International Hippocratique. Université de Lausanne, Publications de la Faculté des Lettres XXVI, Genève, Librairie Droz, pp. 327-330.

Jaeger, Werner-Wilhelm (1990), Paideia: los ideales de la cultura griega, México, Fondo de Cultura Económica.

Jouanna, Jacques (1961), "Présence d'Empédocle dans la collection hippocratique", in Bulletin de l'Association Guillaume Budé: Lettres d'humanité, $\mathrm{n}^{\circ}$ 20, décembre, pp. 452-463. https://doi.org/10.3406/ bude. 1961.4201 
Kauffman, Stuart A. (1998), "La explicación por articulación de partes en la biología y su búsqueda racional”, en Martínez, S. y Barahona, M. (comp.), Historia y explicación en biología, México, Fondo de Cultura Económica, pp. 42-60.

Kirk, C.S., Raven, J.E. y Schofield (1987), Los filósofos presocráticos. Historia crítica con selección de textos, Madrid, Editorial Gredos.

Laín Entralgo, Pedro (1982), La medicina hipocrática, Madrid, Alianza Editorial.

Laín Entralgo, Pedro (1987), El cuerpo humano: Oriente y Grecia Antigua, Madrid, Editorial Espasa Calpe.

Lasso de la Vega, José S. (1963), "Psicología homérica", en R. Adrados, Fernández-Galiano, L. Gil y Lasso de la Vega (eds.), Introducción a Homero, Madrid, Editorial Guadarrama, 1963, Cap. IX, pp. 239-251. Liddell, H. G. \& Scott, R. (1940), A Greek-English Dictionary, 9th ed. rev. by Henry S. Jones, Oxford, Clarendon Press.

Littré, Émile (ed.) (1962), Oeuvres complètes d'Hippocrate, I-IX, Paris, 1839-1861, Amsterdam, Ed. Adolf M. Hakkert.

Lloyd, Geoffrey Ernest Richard (1987), Polaridad y analogía. Dos tipos de argumentación en los albores del pensamiento griego, Madrid, Editorial Taurus.

Lloyd, Geoffrey Ernest Richard (2007), Aristóteles. Desarrollo y estructura de su pensamiento, Buenos Aires, Prometeo Libros.

Martínez, Marcos (2004), "Algunos ejemplos de enantíosis en el Corpus Hippocraticum", Cuadernos de Filología Clásica. Estudios griegos e indoeuropeos, vol. 14, pp. 111-134.

Niño, Douglas (2001), "Peirce, abducción y práctica médica", Anuario filosófico 34, pp. 57-74.

Platón (1988), "Fedro", Diálogos III, Madrid, Editorial Gredos, pp. 309-413. Reale, Giovanni (1999), Corpo, anima e salute : il concetto di uomo da Omero a Platone, Milano, Raffaello Cortina Editore.

Rodríguez de Romo, Ana Cecilia; Aliseda, Atocha y Arauz, Antonio (2008), "Medicina y lógica: el proceso diagnóstico en neurología”, Ludus Vitalis, vol. XVI, núm. 30, pp. 135-163.

Siegel, Rudolph E. (1968), Galen's system of physiology and medicine. An Analysis of his Doctrines and Observations on Blood Flow, Respiration, Humors and Internal Diseases, Basel, Switzerland, S. Karger AG.

Snell, Bruno (2007), El descubrimiento del espíritu. Estudios sobre la génesis del pensamiento europeo en los griegos, Barcelona, Editorial Acantilado. 